\title{
PENGOLAHAN PULP KOPI MENJADI MINUMAN SARI BUAH DENGAN PENAMBAHAN BUAH TERONG BELANDA DAN KONSENTRASI GULA YANG BERBEDA
}

\author{
Nur Halimatuz Zuhra ${ }^{1}$, Dian Hasni ${ }^{2}$, Murna Muzaifa ${ }^{2}$ \\ ${ }^{1}$ Mahasiswa Prodi Teknologi Hasil Pertanian, Fakultas Pertanian, Universitas Syiah Kuala \\ ${ }^{2}$ Staf Pengajar Prodi Teknologi Hasil Pertanian, Fakultas Pertanian, Universitas Syiah Kuala \\ Email: hasni_dian@unsyiah.ac.id
}

\begin{abstract}
ABSTRAK
Kopi umumnya dikonsumsi dalam bentuk seduhan, dimana biji kopi merupakan bahan baku utamanya. Pada pengolahan pembuatan kopi, bagian yang tidak diolah kembali atau yang biasa dijadikan limbah adalah daging kopi (pulp). Pulp kopi sejauh ini baru dimanfaatkan untuk pembuatan pupuk dan pakan ternak. Salah satu produk yang dapat dibuat dari limbah pulp kopi yaitu minuman sari buah. Pembuatan minuman sari buah pulp kopi juga dapat ditambahkan dengan campuran buah lainnya untuk menambah citarasa dari minuman sari buah tersebut. Penambahan gula 20-10\% biasanya dilakukan agar menghasilkan minuman sari buah dengan rasa yang lebih manis. Penelitian ini dilakukan untuk mengetahui pengaruh dari penambahan terong belanda dan gula terhadap mutu sensori, kandungan antioksidan dan total fenol yang terdapat di minuman sari pulp kopi. Penelitian ini menggunakan Rancangan Acak Lengkap (RAL) dengan pola faktorial yang terdiri atas 2 (dua) faktor. Faktor I adalah rasio pulp kopi dan terong belanda (B) 3 taraf yaitu $\mathrm{B}_{1}=100: 0$ (pulp kopi : terong belanda), $B_{2}=90: 10$, dan $B_{3}=80: 20$ dan Faktor II adalah konsentrasi gula $(G) 3$ taraf yaitu $\mathrm{G}_{1}=20 \%$ (dari volume minuman sari pulp kopi), $\mathrm{G}_{2}=15 \%$ dan $\mathrm{G}_{3}=10 \%$. Setiap perlakuan diulang sebanyak 3 kali sehingga didapatkan 27 satuan percobaan. Hasil penelitian menunjukkan bahwa Perbandingan Bahan Baku (B) berengaruh sangat nyata $(\mathrm{P} \geq 0,01)$ terhadap warna minuman sari pulp kopi dan Konsentrasi Gula $(G)$ berpengaruh sangat nyata $(P \geq 0,01)$ terhadap rasa dan aroma minuman sari pulp kopi. Sedangkan interaksi antara Perbandingan Bahan Baku (B) dan Konsentrasi Gula (G) berpengaruh sangat nyata $(\mathrm{P} \geq 0,01)$ terhadap aktivitas antioksidan, $\mathrm{pH}$ dan total padatan terlarut minuman sari pulp kopi.

Kata Kunci-konsentrasi gula; minuman sari pulp kopi; terong belanda
\end{abstract}

\section{PENDAHULUAN}

Dataran Tinggi Gayo di Kabupaten Aceh Tengah dan Bener Meriah merupakan daerah penghasil kopi terbesar di Provinsi Aceh. Luas perkebunan kopi di Bener Meriah menurut BPS (2016) pada tahun 2015 mencapai 46.208,57 Ha dengan total produksi kopi sebanyak 25.790 ton. Sejauh ini, kopi umumnya dikonsumsi dalam bentuk seduhan, dimana menggunakan biji kopi sebagai bahan baku utamanya. Oleh karena bagian buah kopi yang lainnya, seperti pulp dan daging buah kopi dianggap sebagai limbah, dimana persentase pulp ini mencapai $48 \%$ dari total produksi kopi, yang terdiri dari kulit buah 42\% dan kulit biji 6\% (Zaenurdin dan Mutisari, 1995).

Limbah kopi berupa pulp sejauh ini baru dimanfaatkan untuk pembuatan pupuk dan pakan ternak. Kurangnya informasi pada masyarakat tentang manfaat dari pulp kopi mengakibatkan tidak adanya pengolahan dari limbah pulp kopi tersebut di bidang pangan akibatnya pulp kopi belum banyak dimanfaatkan dan dijadikan minuman atau makanan yang kaya akan gizi, seperti sari buah. Minuman sari buah merupakan suatu produk yang sangat mudah diolah dan mudah untuk dikonsumsi. Minuman sari buah dapat dibagi atas dua jenis, yaitu sari buah yang dihasilkan dari proses penghancuran dan penggilingan buah, dan sari buah yang dihasilkan dari konsentrat dengan merekonstitusi konsentrat sari buah dengan air minum (Afrianti et.al., 2014).

Pembuatan minuman sari buah pulp kopi juga dapat ditambahkan dengan campuran buah lainnya untuk menambah citarasa dari minuman sari buah tersebut. Salah satu buah yang dapat ditambahkan yaitu buah terong belanda (Solanum betaceaum) yang juga banyak terdapat di Aceh Tengah. Buah terong belanda daging buah terong belanda banyak mengandung air, sedikit kasar dan memliki rasa sedikit manis. Daging buah terong belanda berwarna kuning yang dilapisi selaput tipis. Biji yang terdapat didalam buah terong belanda berwarna kemerahan (Berawi dan Asvita, 2016). 
Pembuatan minuman sari buah pulp kopi dengan penambahan buah seperti terong belanda diduga dapat memperbaiki warna dan rasa sepat dari kulit buah kopi.

Pada pembuatan minuman sari buah ada dilakukan penambahan bahan seperti gula. Penambahan gula biasanya dilakukan agar menghasilkan minuman sari buah dengan rasa yang lebih manis. Penambahan gula pada pembuatan minuman sari buah berkisar 10-20\% (Octaviani dan Rahayuni, 2014). Penelitian ini dilakukan untuk mengetahui pengaruh dari penambahan terong belanda dan konsentrasi gula terhadap mutu fisikokimia, sensori dan kandungan antioksidan dari minuman sari pulp kopi.

\section{METODOLOGI PENELITIAN}

\section{A. Waktu dan Lokasi}

Penelitiaan ini dilaksanakan pada bulan November 2017 - April 2018 di Laboratorium Rekayasa Proses Pangan dan Industri, Laboratorium Analisis Pangan dan Hasil Pertanian dan Laboratorium Uji Sensori Jurusan Teknologi Hasil Pertanian, Fakultas Pertanian Universitas Syiah Kuala.

\section{B. Bahan dan Alat}

Bahan yang digunakan pada penelitian ini adalah pulp kopi berwarna merah yang berasal dari Takengon, Aceh Tengah, terong belanda yang berwarna kemerahan yang berasal dari Takengon, Aceh Tengah, gula, air, dan CMC. Bahan - bahan kimia yang digunakan DPPH, reagen folin ciocalteau 50\%, Asam galat, Natrium karbonat (NaCO3), etanol 95\%, metanol 70\% dan akuades. Alat yang digunakan pada penelitian ini adalah juicer, spektrofotometri UV-vis, aluminium foil, neraca analitik, kertas label, tabung reaksi, erlenmayer, gelas ukur, kuvet, spatula, gelas kimia, labu ukur, pipet volume, cup, sendok dan form penilaian.

\section{Rancangan Penelitian}

Penelitian ini menggunakan Rancangan Acak Lengkap (RAL) dengan pola faktorial yang terdiri atas 2 (dua) faktor. Faktor I adalah rasio pulp kopi dan terong belanda (B) 3 taraf yaitu $\mathrm{B}_{1}=$ 100:0 (pulp kopi : terong belanda), $\mathrm{B}_{2}=90: 10$, dan $\mathrm{B}_{3}=80: 20$ dan Faktor II adalah konsentrasi gula (G) 3 taraf yaitu $\mathrm{G}_{1}=20 \%$ (dari volume minuman sari pulp kopi), $\mathrm{G}_{2}=15 \%$ dan $\mathrm{G}_{3}=10 \%$. Setiap perlakuan diulang sebanyak 3 kali sehingga didapatkan 27 satuan percobaan.

\section{Prosedur Penelitian}

Buah kopi yang disortasi, dicuci menggunakan air mengalir dan dipisahkan antara daging buah (pulp) dan bijinya. Pulp kopi yang telah dipisahkan, diblender dan disaring menggunakan saringan. 500 gr terong belanda ditambahkan air sebanyak $350 \mathrm{ml}$ (70\% dari buah) diblender, sedangkan 500 gr pulp kopi ditambahkan air $250 \mathrm{ml}$ (50\% dari pulp) dan diblender, kemudian disaring. Proporsi penambahan air dilakukan berdasarkan penelitian pendahuluan sehingga diperoleh penambahan air yang sesui. Sari pulp kopi dan terong belanda dicampurkan dengan rasio (100:0, 90:10 dan 80:20) dan ditambahkan gula sebanyak (20\%, 15\% dan 10\%) serta CMC sebagai penstabil $1 \%$ dari jumlah minuman sari buah. Kemudian sampel disimpan dalam lemari pendingin bersuhu $5^{\circ} \mathrm{C}$ selama 4-6 jam sebelum dianalisis.

Analisis pada penelitian ini dilakukan pada bahan baku awal (kadar air dan kadar abu) dan minuman sari buah pulp kopi meliputi uji aktivitas antioksidan metode DPPH (Rahmawati, 2015), uji total fenol metode Chandler Folin-Ciocalteu (Velioglu et.al.,, 2009), uji total padatan terlarut menggunakan refractometer, uji $\mathrm{pH}$ menggunakan $\mathrm{pH}$ meter dan pengujian penerimaan konsumen secara hedonik (SNI 2346-2006).

\section{E. Analisis Data}

Data yang diperoleh selanjutnya dianalisis secara statistik dengan menggunakan tabel ANOVA (Analisys of Variance). Apabila perlakuan terdapat pengaruh yang nyata $(\mathrm{P} \leq 0.01)$ maka harus dilakukan uji lanjut yaitu dengan menggunakan uji Beda Nyata Terkecil (BNT) untuk parameter $\mathrm{pH}$, total padatan terlarut, total fenol dan aktifitas antioksidan. Sedangkan pada pengujian penerimaan konsumen secara hedonik, dilakukan uji lanjut Duncan Multiple Range Test (DMRT) pada taraf $\alpha=0,05$ untuk perlakuan yang memiliki pengaruh nyata $(\mathrm{P} \leq 0.01)$. 


\section{HASIL DAN PEMBAHASAN}

\section{A. Analisis Awal Bahan Baku}

Bahan baku yang digunakan pada penelitian ini adalah pulp kopi arabika gayo. Pengujian yang dilakukan terhadap pulp kopi meliputi kadar air dan kadar abu. Hasil analisis kadar air dan abu dapat dilihat pada Tabel 1.

Tabel 1. Komposisi Kimia Pulp Kopi

\begin{tabular}{lc}
\hline Komposisi Kimia & Rerata (\%) \\
\hline Kadar air & $46,86 \pm 1,16$ \\
Kadar abu & $2,23 \pm 0,098$ \\
\hline
\end{tabular}

Berdasarkan Tabel 1 terlihat bahwa kadar air pulp kopi mencapai 46,86\% dan kadar abu sebesar 2,23\%. Menurut Panggabean (2011), komposisi dari pulp kopi berupa air 42,66\% dan mineral sebesar $3,77 \%$. Hal tersebut tidak jauh berbeda dari hasil yang didapatkan pada penelitian ini. Namun, untuk kandungan abu pada penelitian ini hanya dilakukan analisis kadar abu kasar. Analisis kadar abu dilakukan untuk mengetahui jumlah kandungan senyawa anorganik yang terdapat pada pulp kopi. Menurut Baon et.al. (2005) kandungan mineral yang terdapat pada pulp kopi berupa nitrogen 2,98\%, fosfor $0,18 \%$ dan kalium 2,26\%. Selain itu, pulp kopi juga mnegandung unsur-unsur seperti $\mathrm{Mg}, \mathrm{Ca}$, $\mathrm{Cu}, \mathrm{Fe}$ dan $\mathrm{Zn}$.

\section{B. Analisis Aktivitas Antioksidan Metode DPPH}

Antioksidan merupakan suatu senyawa yang menyumbangkan satu atau lebih elektron kepada radikal bebas yang dapat menghambat perubahan seperti warna, aroma dan kerusakan pada produk pangan, sehingga dapat memperpanjang masa simpan dari produk pangan (Dungir et.al., 2012). Analisis aktivitas antioksidan pada penelitian ini menggunakan metode DPPH (2,2-Diphenyl-2picrylhydrazyl). DPPH merupakan suatu reagen yang digunakan pada pengujian antioksidan. Prinsip dari metode DPPH yaitu reaksi penangkapan atom hidrogen oleh DPPH dari senyawa antioksidan. Reaksi yang dihasilkan pada pengujian ini yaitu perubahan warna sampel dari ungu menjadi kuning (Lupea et.al., 2006).

Nilai aktivitas antioksidan dinyatakan dalam bentuk persentase inhibisi, yang mempresentasikan seberapa besar kemampuan senyawa antioksidan pada bahan dapat menghambat radikal bebas. Nilai persentase inhibisi minuman sari pulp kopi yang diperoleh berkisar 13,84-41,49\% dengan rerata $23,39 \%$. Analisis ragam menunjukkan bahwa perlakuan perbandingan bahan baku, konsentrasi gula yang berbeda dan interaksi keduanya berpengaruh sangat nyata $(\mathrm{P} \geq 0,01)$ terhadap aktivitas antioksidan. Pengaruh perlakuan interaksi penambahan bahan baku dan konsentrasi gula yang berbeda terhadap aktivitas antioksidan disajikan pada Gambar 1

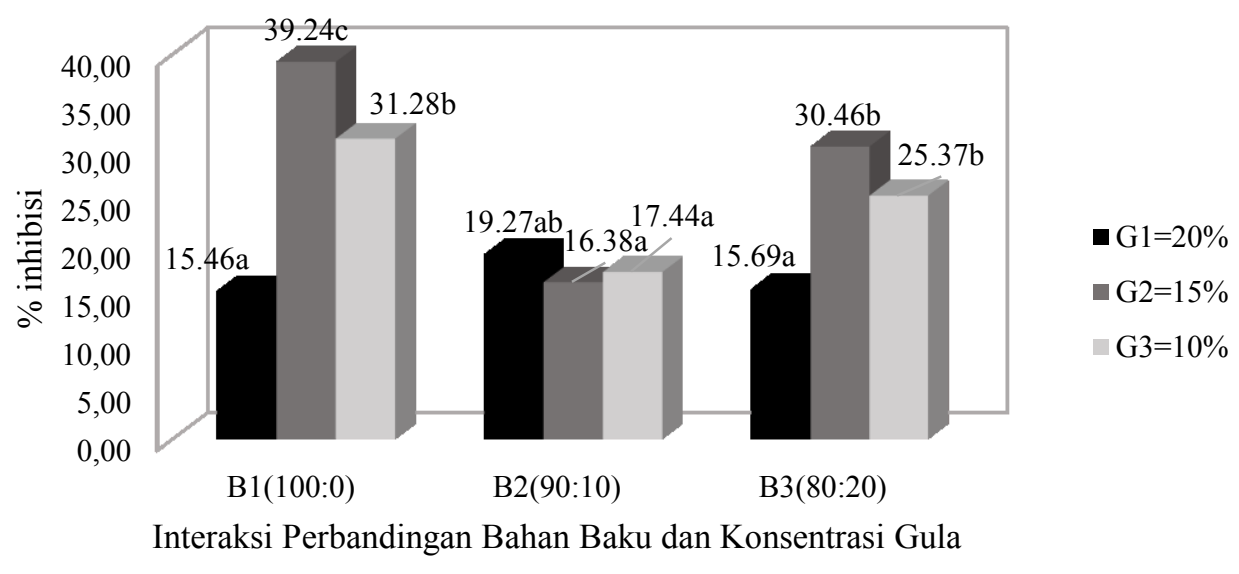

Gambar 1.Pengaruh perlakuan interaksi penambahan bahan baku dan konsentrasi gula yang berbeda terhadap aktivitas antioksidan pada $\mathrm{BNT}_{0,01}=6.66$ dan $\mathrm{KK}=12.11 \%$

(Nilai yang diikuti oleh huruf yang sama menunjukkan perbedaan yang tidak nyata) 
Berdasarkan Gambar 1 terlihat bahwa perlakuan interaksi dari perbandingan bahan baku B1(100:0) dan konsentrasi gula G2(15\%) memiliki persentase inhibisi tertinggi dibandingkan dengan perlakuan lainnya. Perbandingan bahan baku B1(100:0) dengan penambahan konsentrasi gula 15\% dan $10 \%$ cenderung memiliki nilai \% inhibisi yang tinggi. Pada Gambar 1 dapat dilihat bahwa perlakuan konsentrasi gula $20 \%$ pada seluruh perlakuan penambahan bahan baku cenderung memiliki aktivitas penghambat yang lebih rendah dibanding perlakuan dengan konsentrasi gula lainnya. Hal ini diduga dipengaruhi oleh proporsi pulp kopi yang lebih banyak pada perlakuan B1.

\section{Analisis Total Fenol}

Analisis total fenol dilakukan untuk menghitung kandungan senyawa fenolik yang terdapat didalam bahan pangan. Metode yang digunakan untuk menganalisis total fenol yaitu metode FolinCiocalteu (FC). Metode ini menggunakan spektrofotometer untuk mengukur kandungan senyawa fenolik yang terdapat didalam minuman sari pulp kopi. Metode ini juga menggunakan larutan asam galat sebagai larutan standarnya.

Kisaran data total fenol minuman sari pulp kopi yaitu 265,77-523,97 mg GAE/ml dengan rerata total fenol yang didapatkan berkisar 395,85 mg GAE/ml. Hasil sidik ragan menunjukkan bahwa perlakuan penambahan bahan baku, konsentrasi gula yang berbeda dan interaksi penambahan bahan baku dan konsentrasi gula yang berbeda $(\mathrm{P} \leq 0,05)$ tidak berpengaruh terhadap total fenol dari minuman sari pulp kopi. Total fenol yang terdapat pada minuman sari pulp kopi tidak berbeda jauh antar perlakuan dan ulangan.

\section{Analisis Total Padatan Terlarut}

Total padatan terlarut merupakan salah satu parameter mutu minuman sari buah sesuai dengan SNI 3719-2014 yang menyatakan total padatan terlarut pada minuman sari buah berkisar 7,5-16 ${ }^{\circ}$ brix. Pengujian total padatan terlarut dilakukan menggunakan hand refractometer dengan satuan ${ }^{\circ}$ brix. Berdasarkan hasil analisis total padatan terlarut yang telah dilakukan nilai total padatan terlarut dari minuman sari pulp kopi dan terong belanda berkisar $10,20-20^{\circ}$ brix rerata sebesar $15,82^{\circ}$ brix. Berdasarkan hasil sidik ragam menunjukkan bahwa rasio penambahan bahan baku, konsentrasi gula dan interaksi keduanya berpengaruh sangat nyata $(\mathrm{P} \geq 0,01)$ terhadap total padatan terlarut minuman sari pulp kopi. Pengaruh tingkat interaksi penambahan terong belanda dan konsentrasi gula dapat dilihat pada Gambar 2.

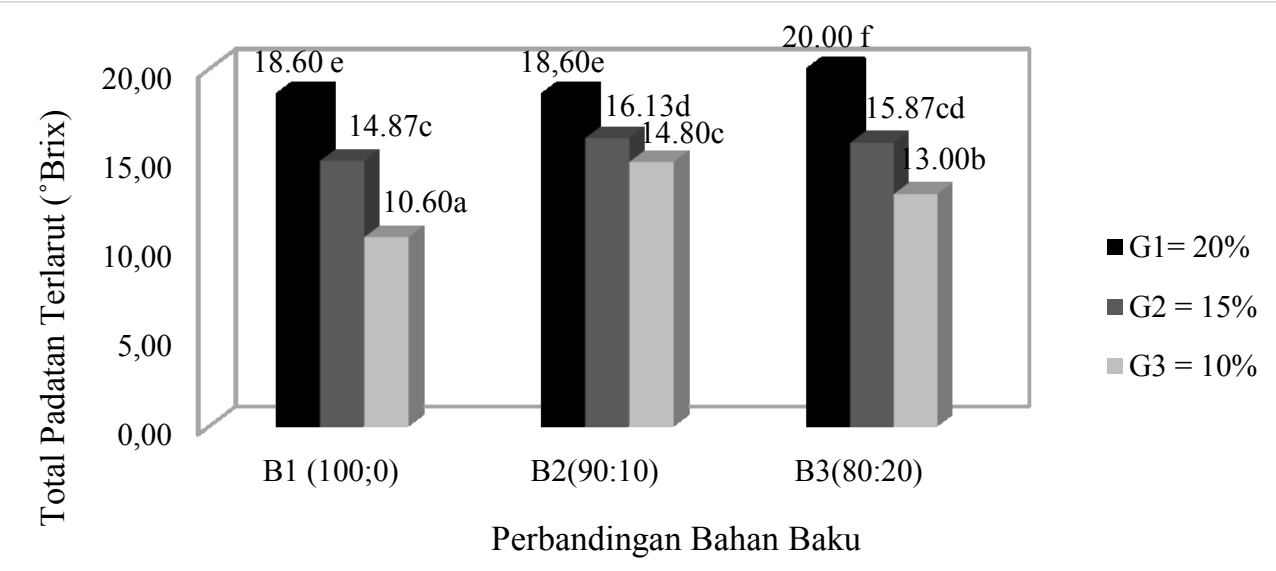

Gambar 2. Pengaruh perlakuan interaksi penambahan bahan baku dan konsentrasi gula yang berbeda terhadap total padatan terlarut pada $\mathrm{BNT}_{0,01}=1.193$ dan $\mathrm{KK}=3.20 \%$

(Nilai yang diikuti oleh huruf yang sama menunjukkan perbedaan yang tidak nyata)

Berdasarkan Gambar 2 terlihat bahwa kombinasi B3G1 sebagai perlakuan dengan nilai total padatan terlarut tertinggi yang berbeda dengan seluruh total padatan terlarut perlakuan lainnya. Sedangkan kombinasi perlakuan B1G3 memiliki nilai total padatan terlarut terendah. Terlihat kecenderungan bahwa setiap penambahan konsentrasi terong belanda dan konsentrasi gula menyebabkan tingginya total padatan terlarut. Gula diketahui berperan dalam meningkatkan total 
padatan terlarut dan pada terong belanda juga diketahui tinggi mengandung gula. Hal ini sesuai dengan yang dikatakan oleh Bangun (2009) semakin tinggi konsentrasi gula maka total padatan terlarut juga semakin tinggi. Begitu juga dengan Olivianti (2012) yang menyatakan bahwa, kandungan gula pada buah merupakan sukrosa. Gula sukrosa yang larut didalam suatu larutan dapat menghasilkan total padatan terlarut yang tinggi.

\section{E. Analisis pH}

Pada penelitian ini juga dilakukan uji fisik berupa uji pH terhadap minuman sari pulp kopi. Pengujian ini dilakukan menggunakan $\mathrm{pH}$ meter. Kisaran $\mathrm{pH}$ dari minuman sari buah pulp kopi yaitu 4,60-4,94 dengan rerata 4,74. Berdasarkan hasil sidik ragam menggunakan ANOVA menunjukkan bahwa penambahan bahan baku dan interaksi dari penambahan bahan baku dan konsentrasi gula berpengaruh sangat nyata $(\mathrm{P} \geq 0.01)$ terhadap $\mathrm{pH}$ minuman sari pulp kopi. Pengaruh interaksi tersebut dapat dilihat pada Gambar 3 .

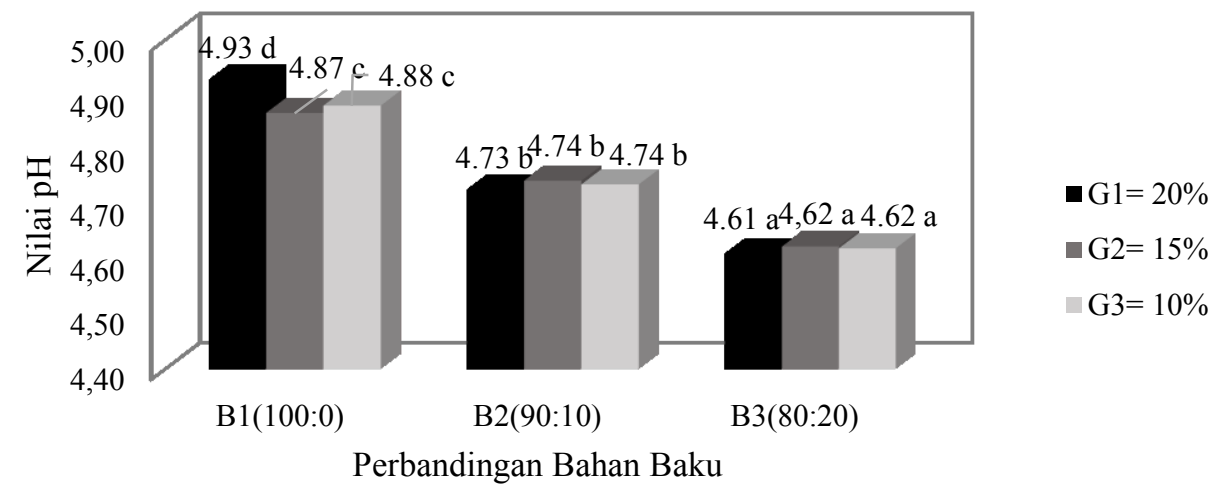

Gambar 3.Pengaruh perlakuan interaksi penambahan bahan baku dan konsentrasi gula yang berbeda terhadap $\mathrm{pH}$ minuman sari pulp kopi pada $\mathrm{BNT} 0,01=0.041$ dan $\mathrm{KK}=0.371 \%$

(Nilai yang diikuti oleh huruf yang sama menunjukkan perbedaan yang tidak nyata)

Dari Gambar 3 dapat dilihat bahwa kombinasi perlakuan B1G1 yang merupakan kombinasi dari perbadningan bahan baku 100:0 dan penambahan gula 20\% menghasilkan sari pulp kopi dengan $\mathrm{pH}$ tertinggi dan berbed nyata dengan seluruh perlakuaan lainnya, sedangkan $\mathrm{pH}$ terendah diperoleh dari kombinasi perlakuan B3G1, kombinasi perbandingan bahan baku 80:20 pada taraf penambahan gula 10\%. Perlakuan ini berbeda tidak nyata dengan kedua kombinasi perlakuan B3 lainnya, yaitu B3G2 dan B3G3. Dari Gambar 3 dapat juga disimpulkan bahwa penambahan proporsi terong belanda pada faktor perbandingan bahan baku dapat menurunkan $\mathrm{pH}$ minuman sari pulp kopi yang dihasilkan. Hal ini diduga karena terong belanda sendiri memiliki $\mathrm{pH}$ yang lebih asam dibandingkan dengan $\mathrm{pH}$ pulp kopi, yaitu berkisar antara $4.5-4.9$, sedangkan pulp kopi dari perlakuan B1 daapt kita lihat memiliki $\mathrm{pH}$ yang berkisar antara 4.88-4.93.

\section{F. Uji Sensori Warna}

Menurut Sembiring et.al.(2013) warna merupakan suatu faktor yang sangat penting untuk diperhatikan. Warna juga dapat difungsikan sebagai daya tarik utama dari suatu makanan atau minuman karena warna dapat dinilai langsung tanpa harus mencicipi produk terlebih dahulu. Dari hasil analisis menggunakan uji hedonik, nilai hedonik warna yang diberikan oleh panelis berkisar 2,70-3,43(netral). Rerata (Lampiran 10b) yang didapatkan berkisar 3,38 (netral). Hasil dari analisis ragam yang dilakukan menggunakan metode ANOVA menunjukkan bahwa hanya faktor perbandingan bahan baku yang berpengaruh sangat nyata $(\mathrm{P} \geq 0,01)$, sedangkan faktor konsentrasi gula tidak berpengaruh nyata $(\mathrm{P} \leq 0,05)$ terhadap warna minuman sari pulp kopi yang dihasilkan. 


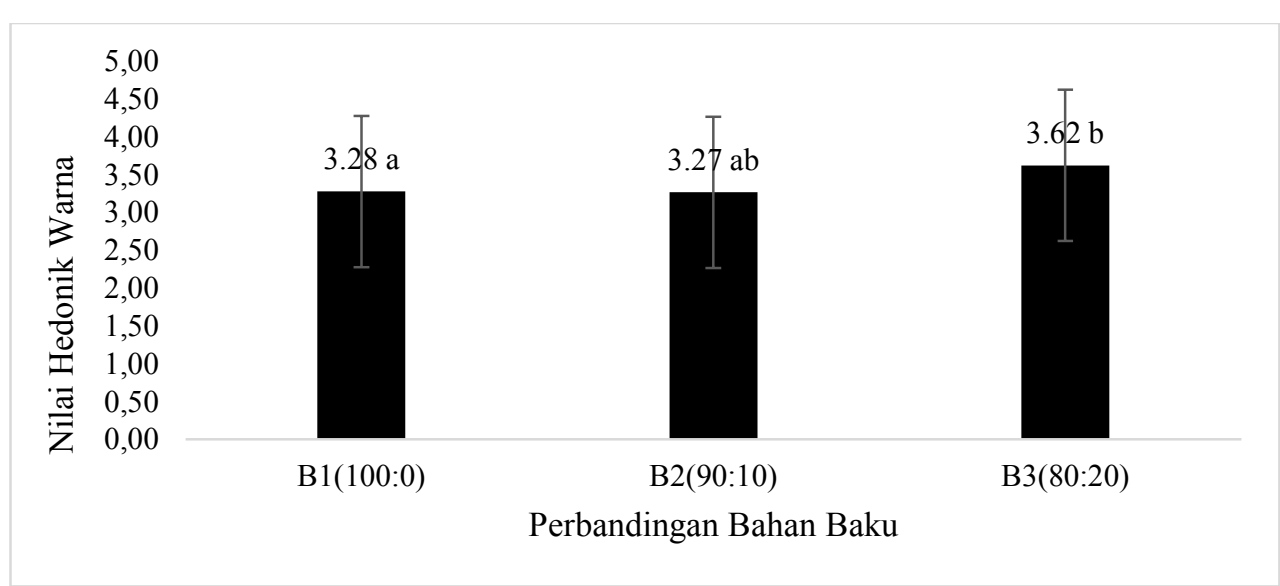

Gambar 4. Pengaruh perlakuan penambahan bahan baku terhadap warna minuman sari pulp kopi pada DMRT0,05 taraf $1=0,24$; taraf $2=0,75$ dan $\mathrm{KK}=24,21 \%$

(Nilai yang diikuti oleh huruf yang sama menunjukkan perbedaan yang tidak nyata)

Gambar 4 menunjukkan perngaruh perbandingan bahan baku terhadap nilai hedonik warna minuman sari pulp kopi yang dihasilkan. Uji lanjut menggunkan metode Duncan menunjukkan taraf B3 (80:20) berbeda nyata dengan B1(100:0), dimana semakin banyak perbandingan terong belanda maka penerimaan panelis terhadap warna minuman sari pulp kopi semakin baik. Semakin banyak sari buah terong belanda yang ditambahkan, maka warna dari minuman sari pulp kopi menjadi lebih baik.

\section{G. Uji Sensori Rasa}

Uji citarasa dari suatu produk merupakan hal yang sangat penting untuk dilakukan. Uji kesukaan rasa yang dilakukan untuk mengetahui tingkat kesukaan konsumen terhadap produk baru. Produk makanan atau minuman yang akan dikomersialkan sebaiknya memiliki rasa yang disukai oleh konsumen agar dapat laku dipasaran. Nilai kesukaan panelis terhadap rasa dari minuman sari pulp kopi berkisar 2,36-3,26 (tidak suka hingga netral). Hasil penilitian ini menunjukkan rerata tingkat kesukaan konsumen terhadap minuman sari pulp kopi sebesar 3,19 (netral). Hasil dari analisis ragam menyatakan bahwa pada tingkat kepercayaan $(\mathrm{P} \geq 0,01)$ hanya perlakuan konsentrasi gula berpengaruh sangat nyata, sedangkan perlakuan perbandingan bahan baku dan interaksi keduanya tidak berpengaruh nyata $(\mathrm{P} \leq 0,05)$ terhadap rasa dari minuman sari pulp kopi. Nilai hedonik rasa Gambar 5 menunjukkan pengaruh faktor konsentrasi gula sangat berpengaruh terhadap rasa minuman sari pulp kopi.

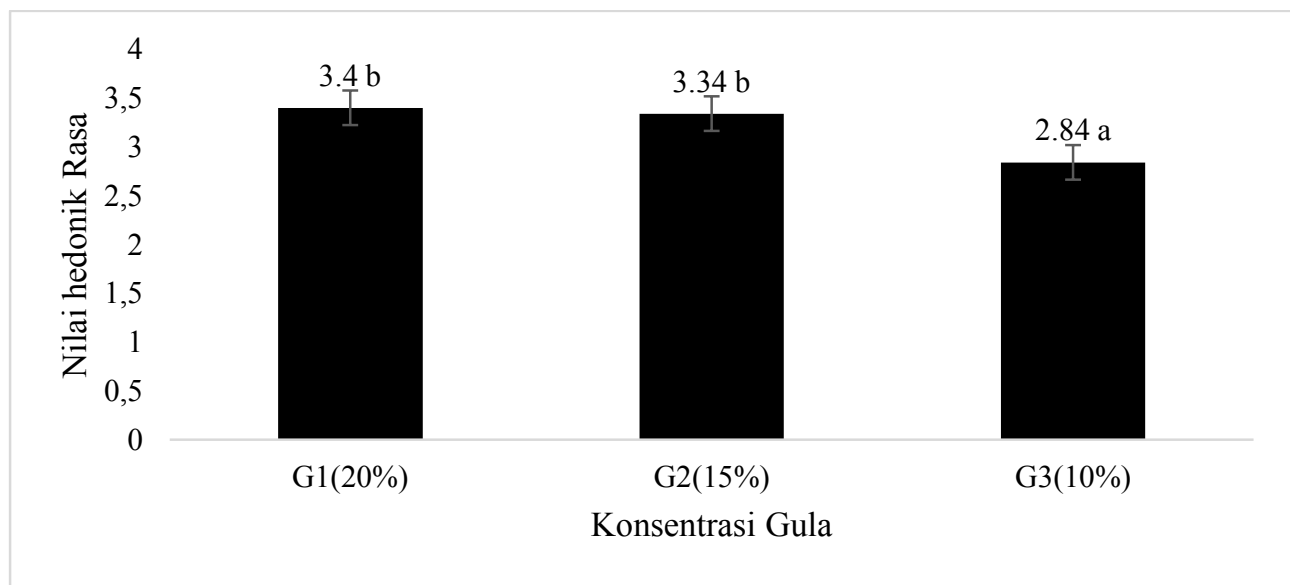

Gambar 5. Pengaruh perlakuan konsentrasi gula yang berbeda terhadap rasa minuman sari pulp kopi pada DMRT0,05 taraf $1=0,26$; taraf $2=0,27$ dan $\mathrm{KK}=28,02 \%$

(Nilai yang diikuti oleh huruf yang sama menunjukkan perbedaan yang tidak nyata)

Uji lanjut Duncan menunjukkan bahwa penambahan konsentrasi gula pada taraf G3(10\%) berbeda nyata dengan kedua taraf lainnya, sedangkan taraf G1 dan G2 menghasilkan penerimaan panelis terhadap nilai hedonik rasa yang tidak berbeda nyata. Berdasarkan Gambar 5 terlihat bahwa 
minuman sari pulp kopi dengan perlakuan konsentrasi G2(15\%) memiliki nilai kesukaan yang tinggi dan sudah diterima oleh panelis. Sama halnya dengan yang dinyatakan dengan Octaviani dan Rahayu (2014) pada pengolahan minuman sari buah konsentrasi gula yang ditambahkan sekitar $10-20 \%$.

\section{H. Uji Sensori Aroma}

Selain uji warna dan rasa, penelitian ini juga menguji aroma dari minuman sari pulp kopi. Pengujian aroma pada minuman sari pulp kopi dilakukan menggunakan uji hedonik. Nilai hedonik aroma dari minuman sari pulp kopi yang diuji oleh panelis berkisar 2,33-2,84 (tidak suka hingga netral). Rerata yang didapatkan dari hasil penelitian terhadap aroma minuman sari pulp kopi berkisar 2,96 (netral). Hasil analisis sidik ragam menggunakan ANOVA menyatakan bahwa konsentrasi gula berpengaruh nyata $(P \geq 0,05)$, sedangkan perlakuan perbandingan bahan baku dan interaksi keduanya tidak berpengaruh nyata $(\mathrm{P} \leq 0,05)$ terhadap aroma dari minuman pulp kopi.

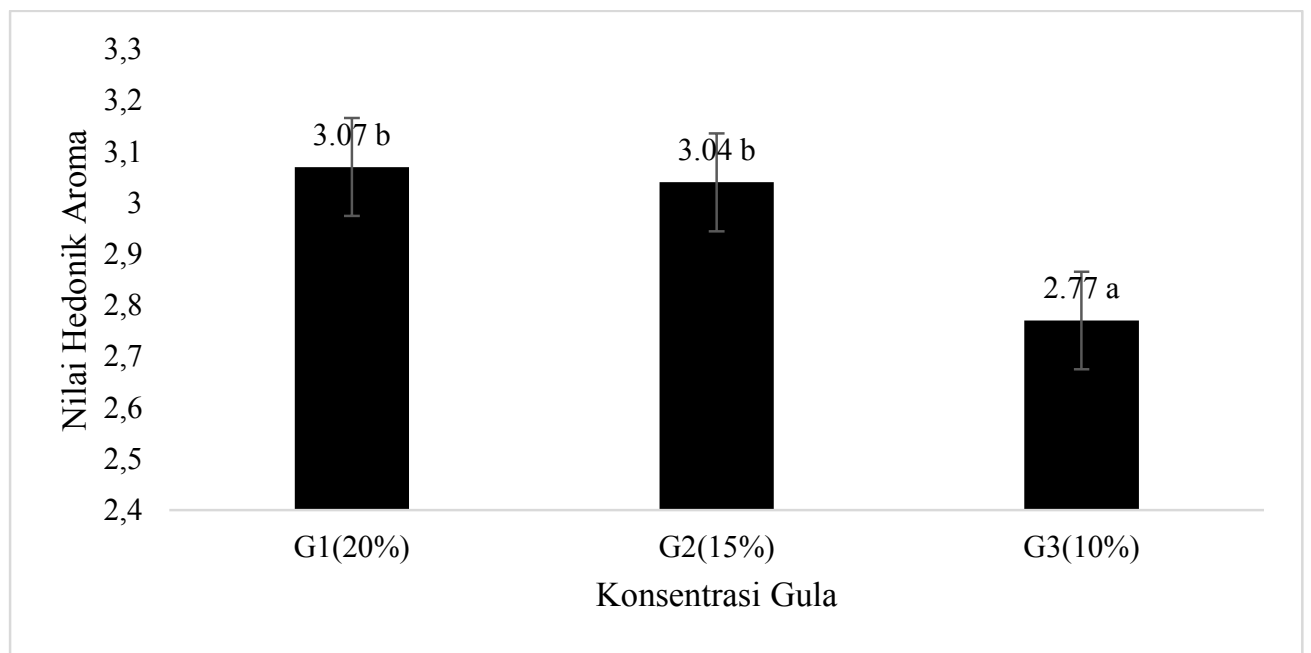

Gambar 6. Pengaruh perlakuan konsentrasi gula yang berbeda terhadap aroma minuman sari pulp kopi pada DMRT0,05 taraf $1=0,24$; taraf $2=0,25$ dan $\mathrm{KK}=28,46 \%$

(Nilai yang diikuti oleh huruf yang sama menunjukkan perbedaan yang tidak nyata)

Uji lanjut Duncan menunjukkan bahwa penambahan konsentrasi gula pada taraf G3(10\%) berbeda nyata dengan kedua taraf lainnya, sedangkan taraf G1 dan G2 menghasilkan penerimaan panelis terhadap nilai hedonik aroma yang tidak berbeda nyata. Berdasarkan Gambar 11, terlihat bahwa konsentrasi gula yang diberikan pada minuman sari pulp kopi berpengaruh terhadap aroma dari minuman sari pulp kopi. Minuman sari pulp kopi yang diberikan gula dengan konsentrasi $15 \%$ memiliki nilai kesukaan yang tinggi sehingga diterima oleh panelis. Karena konsentrasi gula yang tinggi dapat mempengaruhi aroma dari minuman sari pulp kopi. Menurut Hadiwijaya (2013) selain memiliki fungsi untuk memperbaiki citarasa dan menyeimbangkan rasa dari suatu produk, gula juga berfungsi untuk meningkatkan aroma dari produk tersebut.

\section{KESIMPULAN}

Perlakuan perbandingan bahan baku pulp kopi dan terong belanda berpengaruh sangat nyata $(P \geq 0,01)$ terhadap mutu sensori warna minuman sari pulp kopi. Perlakuan penambahan konsentrasi gula berpengaruh sangat nyata $(P \geq 0,01)$ terhadap mutu sensori rasa dan berpengaruh nyata $(P \geq 0,05)$ terhadap aroma minuman sari pulp kopi. Perlakuan interaksi perbandingan bahan baku dan konsentrasi gula berpengaruh sangat nyata $(\mathrm{P} \geq 0,01)$ terhadap aktivitas antioksidan, $\mathrm{pH}$ dan total padatan terlarut minuman sari pulp kopi. Berdasarkan nilai rerata parameter yang diuji, minuman sari pulp kopi yang dihasilkan memiliki aktivitas antioksidan 23,39 $\pm 8,58$, total padatan terlarut $15,82 \pm 2,87, \mathrm{pH} 4,74 \pm 0,11$,

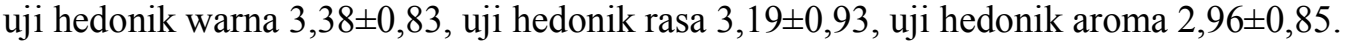




\section{DAFTAR PUSTAKA}

Afrianti,L.H., Y.Taufik, dan H.Gustianova. 2014. Karaktersitik Fisiko-Kimia Dan Sensorik Minuman sari buah Ekstrak Buah Salak (Salacca Edulis Reinw) Varietas Bongkok. Chimica et Natura Acta.Vol.2 No.2, Hal.126-130.

Bangun, N.H.P. 2009. Pengaruh Konsentrasi Gula dan Campuran Sari Buah (Markisah, Wortel dan Jeruk) Terhadap Mutu Serbuk Minuman Penyegar. Skripsi. Universitas Sumatera Utara, Medan.

Baon, J.B., R.Sukasih dan Nurkholis. 2005. Laju Dekomposisi dan Kualitas Kompos Limbah Padat Kopi: Pengaruh Aktivator dan Bahan Baku Kompos, Pelita Perkebunan, 21, 31-42.

BPS. 2016. Statistik Daerah Kabupaten Bener Meriah. Bener Meriah, Aceh.

Dungir, S.G., D.G. Katja dan V.S. Kamu. 2012. Aktivitas Antioksidan Ekstrak Fenolik dari Kulit Buah Manggis (Garcinia mangostana L.). Jurnal Mipa Unsrat Online. Vol.1, No.1, Hal.11-15.

Hadiwijaya, H. 2013. Pengaruh Perbedaan Penambahan Gula Terhadap Karakteristik Sirup Buah Naga Merah. Jurusan Teknologi Hasil Pertanian. Universitas Andalan, Padang.

Octaviani, L.F dan A. Rahayuni. 2014. Pengaruh Berbagai Konsentrasi Gula Terhadap Aktivitas Antioksidan dan Tingkat Penerimaan Sari Buah Buni. Journal of Nutrition College, Vol.3, No.4, Hal 958-965.

Olivianti,R. 2012. Pengaruh Penambahan Garam dan Lama Penggaraman Terhadap Aktivitas Antioksidan Minuman Sari Pare (Momordica Charantia L). Skripsi. Fakultas Teknologi Pertanian. Universitas Brawijaya, Malang.

Sembiring, L.R., L.M.E. Purwijantiningsih dan S.Prananta. 2013. Pemanfaatan Biji Terong Belanda (Cyphomandra betacea Sendtn) Sebagai Pewarna Alami Es Krim. Universitas Atma Jaya, Jogjakarta.

SNI 3719-2014. Minuman Sari Buah. Badan Standardisasi Nasional, Jakarta.

Zainuddin, D. dan T. Murtisari. 1995. Penggunaan limbah agro-industri buah kopi (kulit buah kopi) dalam ransum ayam pedaging (Broiler). Pertemuan Ilmiah Komunikasi dan Penyaluran Hasil Penelitian. Sub Balai Penelitian Klepu, Puslitbang Peternakan, Bogor. Hal.71 - 78. 